http://dx.doi.org/10.5050/KSNVE.2012.22.6.556

$$
\begin{gathered}
\text { 배치형식에 따른 복합형 마운트의 동특성 및 } \\
\text { 제어성능에 대한 비교연구 }
\end{gathered}
$$

\title{
A Comparative Study on the Dynamic Characteristics and Control Performances of Hybrid Mounts According to Element Configuration
}

\author{
조 혜 영*.문 석 준†. 신 윤 호*.정 우 진**. 원 문 철*** \\ H. Y. Cho, S. J. Moon, Y. H. Shin, W. J. Jung and M. C. Won \\ (2012년 4월 3일 접수 ; 2012년 5월 16일 심사완료)
}

Key Words : Hybrid Mount(복합형 마운트), Dynamic Characteristics(동특성), Control Performance(제어성능), Configuration(배치형식)

\begin{abstract}
This study focuses on the element configuration of hybrid mounts which are combined with passive elements and active elements. The seven configurations are presented according to connection of an active element to a passive element. The dynamic characteristics and control performance of them are investigated qualitatively using Bode plots. With reference to the transmitted force from internal to external, three cases are selected. In addition, some numerical simulations for the three cases are carried out to confirm the performance quantitatively. Based on this research results, a novel hybrid mount with excellent performance will be able to be developed.
\end{abstract}

\section{1. 서 론}

장비의 하부에 설치되는 마운트(mount)는 장비 자체의 정하중(자중)을 지지하는 역할 뿐만 아니라 외부 진동으로부터 장비를 보호하여 장비 고유의 기능을 수행하도록 지원하는 역할을 담당한다. 특별 한 경우에는 외부의 충격 하중으로부터 장비를 보 호하는 역할을 담당하거나, 장비로부터 유발되는 진 동이 외부로 전달되는 것을 방지하는 역할을 담당 하기도 한다. 대부분의 상용 마운트들은 공기 스프

† 교신저자; 정회원, 한국기계연구원

E-mail : sjmoon@kimm.re.kr

Tel : (042) 868-7428, Fax : (042) 868-7418

* 한국기계연구원

** 정회원, 국방과학연구소

*** 충남대학교
링, 고무 탄성 마운트 등의 수동형이며, $10 \mathrm{~Hz}$ 이하 의 낮은 고유진동수를 보유함으로서 높은 주파수영 역에서 우수한 방진성능을 가지고 있다.

산업의 발전과 더불어 더욱 우수한 방진 또는 내 충격 성능을 보유하고 있는 마운트의 개발이 요구 되고 있으며, 수동형 마운트와 능동형 작동기가 결 합된 복합형 마운트에 대한 연구가 널리 수행되고 있다. 전기/전자 분야의 정밀 생산/검사장비 등의 미진동에 대한 진동허용 기준이 강화되고 있으며, 이를 만족시키기 위하여 수동형 공기스프링과 압전 형 작동기, 전자기식형 작동기 또는 공압조절형 작 동기를 결합한 연구 결과가 발표되고 있다 ${ }^{(1 \sim 4)}$. 발표 된 복합형 마운트는 장비로 유입되는 외부진동을 차단함으로서 장비 고유의 성능을 구현하는데 목적 이 있다. 한편, 자동차 분야에서는 자동차 엔진에서 발생하는 내부진동이 차체로 전달되어 승객의 안락 
성 및 쾌적성이 저하되는 것을 더욱 효과적으로 방 지하기 위해 수동형 고무 마운트와 전자기식형 작 동기 또는 $\mathrm{MR} / \mathrm{ER}$ 형 유체작동기 등을 결합한 복합 형 마운트에 대한 연구가 발표되고 있다 ${ }^{(5,6)}$. 국방 분야에서는 장비에서 발생하는 내부진동에 의한 고 체음이 외부로 전달되는 것을 차단함으로서 적으로 부터의 탐지율을 저감하기 위해 수동형 고무 마운 트와 압전형 작동기를 결합한 연구가 진행되고 있 다 ${ }^{(7,8)}$. 특별히 국방 분야에 적용되고 있는 복합형 마운트의 경우에는 진동차단성능과 더불어 내충격 성능도 요구하고 있다.

발표된 연구결과들을 살펴보면, 적용분야에 따라 다른 형태의 복합형 마운트가 개발되고 있는 것을 알 수 있다. 따라서 복합형 마운트를 개발하기 위해 서는 설계단계에서부터 수동형 마운트와 능동형 작 동기의 배치방법에 대한 심도 있는 연구가 필요하 다. 복합형 마운트의 활용 목표는 외부진동이 내부 로 유입되는 성분의 차단과 내부진동이 외부로 전 달되는 성분의 차단으로 대별될 수 있다. 이 연구에 서는 대별되는 2 가지 목표 중 후자 즉, 내부진동이 외부로 전달되는 성분의 차단에 대해 복합형 마운 트의 구성요소 배치형식에 의한 복합 마운트의 동 특성 및 제어성능을 고찰해 보았다. 이러한 기초연 구를 토대로 새로운 형태의 복합형 마운트를 개발 하고자 한다.

\section{2. 배치형식에 따른 동특성}

\section{1 마운트 요소의 배치형식}

수동형 요소를 기본으로 하는 복합형 마운트에 설치되는 능동형 요소는 연결방식에 따라 직렬형 연결과 병렬형 연결로 나눌 수 있다. 즉, 수동형 요 소의 위쪽 또는 아래쪽에 능동형 요소를 직렬로 연 결하는 방식과 수동형 요소의 주변에 병렬로 연결 하는 방식이 있다. 직렬형 연결방식에서는 일반적으 로 능동형 요소가 수동형 요소에 물리적으로 결합 하는 접촉식 연결 형태를 가지고 있다. 반면, 병렬 형 연결방식에는 접촉식 또는 비접촉식 연결 형태 를 가질 수 있다. 능동형 요소 측면에서 살펴보면, 수동형 요소에 직접 제어력을 전달하는 직렬형 방 식, 비접촉 상태에서 제어력을 전달하는 병렬형 방 식 및 관성질량을 이용하는 관성력형 방식 등으로
나눌 수 있을 것이다.

수동형 마운트만 설치된 장비에 대한 1-자유도 모델링은 Fig. 1(a)와 같이 표현될 수 있으며, 운동 방정식은 식 (1)과 같다.

$$
m_{\text {equip }} \ddot{z}+c_{m} \dot{z}+k_{m} z=F
$$

여기서, $m, c, k$ 및 $F$ 는 각각 질량, 감쇠, 강성 및 외력을 나타내며, 아래 첨자 equip 및 $m$ 은 각각 장비 및 마운트를 표현하고 있다. Fig. 1(a)의 수동 형 마운트에 비접촉식 능동형 요소가 병렬형식으로 설치된다면, Fig. 1(b)와 같이 나타낼 수 있다. 단, 능동형 요소의 동특성은 무시한 경우이다. Fig. 1(b) 의 운동방정식은 식(2)로 표현될 수 있다.

$$
m_{\text {equip }} \ddot{z}+c_{m} \dot{z}+k_{m} z=F+f_{c}
$$

여기서 $f_{c}$ 는 능동형 요소에 의해 작용하는 제어력 이다. 반면, 접촉식 능동형 요소가 병렬형식으로 설 치된다면, Fig. 1(c)과 같이 나타낼 수 있다. 이 경 우, 능동형 요소의 동특성은 상대적으로 중요함으로 무시할 수 없다. Fig. 1(c)의 운동방정식은 식 (3)으 로 표현될 수 있다.

$$
m_{\text {equip }} \ddot{z}+\left(c_{m}+c_{c}\right) \dot{z}+\left(k_{m}+k_{c}\right) z=F+f_{c}
$$

여기서 $c_{c}, k_{c}$ 는 능동형 요소의 감쇠와 강성을 나타 낸다.

Fig. 1(d)는 관성력형 능동 요소가 장비에 연결된 형태를 보여주고 있다. 이 경우의 운동방정식은 식 (4)과 같이 표현될 수 있다.

$$
m_{\text {equip }} \ddot{z}+c_{m} \dot{z}+k_{m} z=F+f_{c}
$$

다음은 수동형 마운트 아래에 능동형 요소가 설치된 경우이다. 능동형 요소가 수동형 마운트와 직렬 형태로 연결될 것이며, 능동형 요소에서 발 생한 제어력이 전달되는 위치에 따라서 Fig. 1(e), (f) 및 (g)로 나눌 수 있다. Fig. 1(e)는 제어력이 장비와 능동형 요소 사이에 작용하는 것을 보여 주고 있으며, Fig. 1(f)는 능동형 요소와 하단 지지 부 사이에 작용하고 있다. Fig. $1(\mathrm{~g})$ 는 관성력형 능동 요소에 의한 제어력이 작용하는 것을 보여 주고 있다. 각각의 모델링을 운동방정식으로 나타 


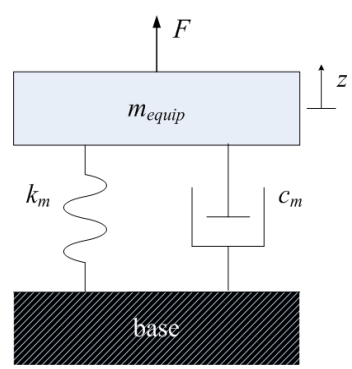

(a) Case 1

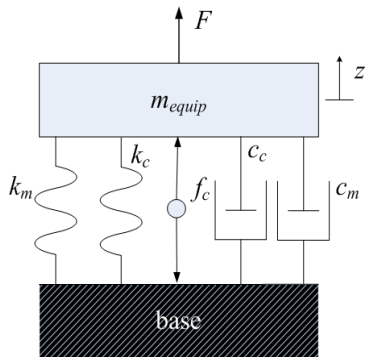

(c) Case 3

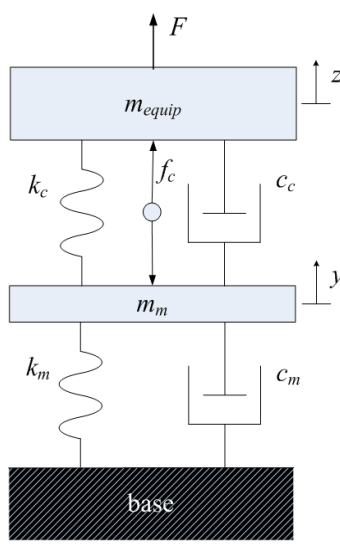

(e) Case 5

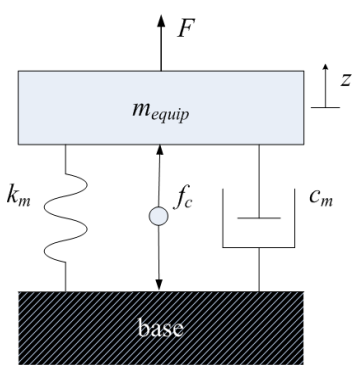

(b) Case 2

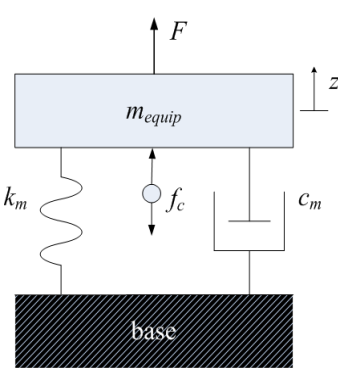

(d) Case 4

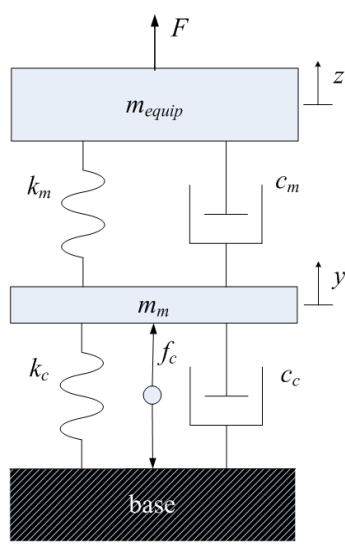

(f) Case 6

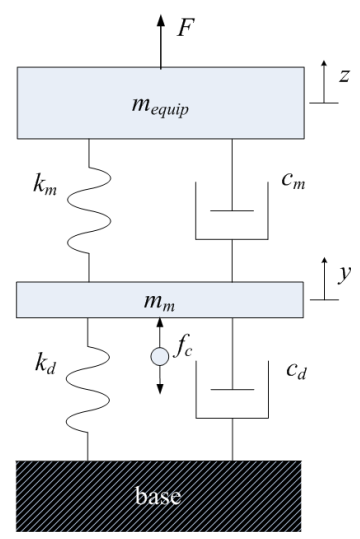

(g) Case 7

Fig. 1 Schematic modeling for hybrid mounts
내면, 각각 식 (5), (6) 및 (7)과 같다.

$$
\begin{aligned}
& m_{\text {equip }} \ddot{z}+c_{c}(\dot{z}-\dot{y})+k_{c}(z-y)=F+f_{c} \\
& m_{m} \ddot{y}+c_{m} \dot{y}+k_{m} y+c_{c}(\dot{y}-\dot{z})+k_{c}(y-z)=-f_{c} \\
& m_{\text {equip }} \ddot{z}+c_{m}(\dot{z}-\dot{y})+k_{m}(z-y)=F \\
& m_{m} \ddot{y}+c_{c} \dot{y}+k_{c} y+c_{m}(\dot{y}-\dot{z})+k_{m}(y-z)=f_{c} \\
& m_{\text {equip }} \ddot{z}+c_{m}(\dot{z}-\dot{y})+k_{m}(z-y)=F \\
& m_{m} \ddot{y}+c_{d} \dot{y}+k_{d} y+c_{m}(\dot{y}-\dot{z})+k_{m}(y-z)=f_{c}
\end{aligned}
$$

여기서, $m_{m}$ 은 능동형 요소의 질량부분을 표현한 것이며, $c_{d}, k_{d}$ 는 하부구조의 감쇠와 강성을 모델링 한 것이다.

\section{2 동특성 비교}

Fig. 1의 7개 경우에 대한 동특성을 비교하기 위 해 실제 인자를 식(1) 식 (7)에 대입하였다. 수동형 마운트 상부에 설치된 장비의 무게 $\left(m_{\text {equip }}\right)$ 는 500 $\mathrm{kg}$ 이며, 마운트의 감쇠계수 $\left(c_{m}\right)$ 와 강성계수 $\left(k_{m}\right)$ 는 각각 $2,778 \mathrm{~N} /(\mathrm{m} / \mathrm{s})$ 와 $859,849 \mathrm{~N} / \mathrm{m}$ 로 설정하였다. Case 1 인 경우, 장비에 작용하는 힘 $(F)$ 과 수동 마 운트를 거쳐 하부로 전달되는 힘 $\left(F_{T}=c_{m} \dot{z}+k_{m} z\right)$ 과 의 bode 선도는 Fig. 2 와 같다. 약 $6 \mathrm{~Hz}$ 근처에 수 동 마운트에 의한 고유진동수가 있는 것을 알 수 있으며, 고주파수 영역에서는 전달률이 저감하는 것 을 확인할 수 있다.

Case 2인 경우, 식 (2)에서 장비의 진동을 최소화 하기 위해서는 외력과 동일한 크기의 제어력 $\left(f_{c}=-F\right)$ 이 필요한 반면, 하부로 전달되는 진동을 최소화하기 위해서는 전달되는 힘과 동일한 크기의 제어력 $\left(f_{c}=c_{m} \dot{z}+k_{m} z\right)$ 이 필요함을 알 수 있다. Fig. 3 은 제어력 $\left(f_{c}\right)$ 이 하부로 전달되는 힘 $\left(F_{T}\right)$ 과의 전달 률(bode 선도)을 보여주고 있으며, 고주파수 영역에 서 제어력이 손실 없이 전달되는 것을 볼 수 있다. 따라서 case 2의 복합형 마운트는 하부로 전달되는 진동을 효과적으로 제어할 수 있음을 알 수 있다. Case 3 에서 능동형 요소의 감쇠계수 $\left(c_{c}\right)$ 및 강성계 수 $\left(k_{c}\right)$ 는 각각 $0 \mathrm{~N} /(\mathrm{m} / \mathrm{s})$ 및 $400 \mathrm{E} 6 \mathrm{~N} / \mathrm{m}$ 로 가정하였 다. Table 1 에 복합형 마운트의 수치해석에 사용된 파라미터를 정리하였다.

Fig. 4는 case 3 에 대한 bode 선도를 보여주고 있 
는데, 능동형 요소의 강성 추가로 인하여 고유진동 수가 우측으로 이동한 것을 알 수 있다. 일반적으로 능동형 요소의 강성이 상대적으로 크므로, case 3의 복합형 마운트에서는 수동형 마운트의 고유한 장점 (고주파수 영역에서의 방진효과)이 퇴색된 것을 알 수 있다. 따라서 복합형 마운트의 배치형태로서는 적합하지 않은 것으로 판단된다. Case 4인 경우, 식 (4)에서 진동을 최소화하기 위해서는 외력과 동일한 크기의 제어력 $\left(f_{c}=-F\right)$ 이 필요하며, Fig. 5 에 제어

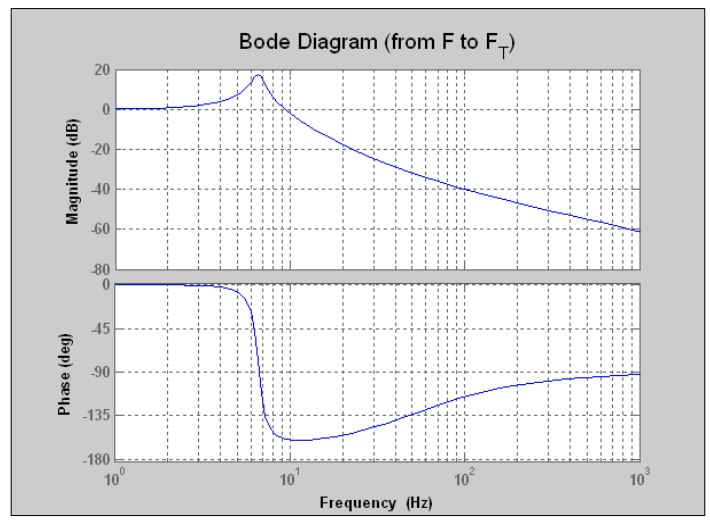

Fig. 2 Bode plot from $F$ to $F_{T}$ : case 1

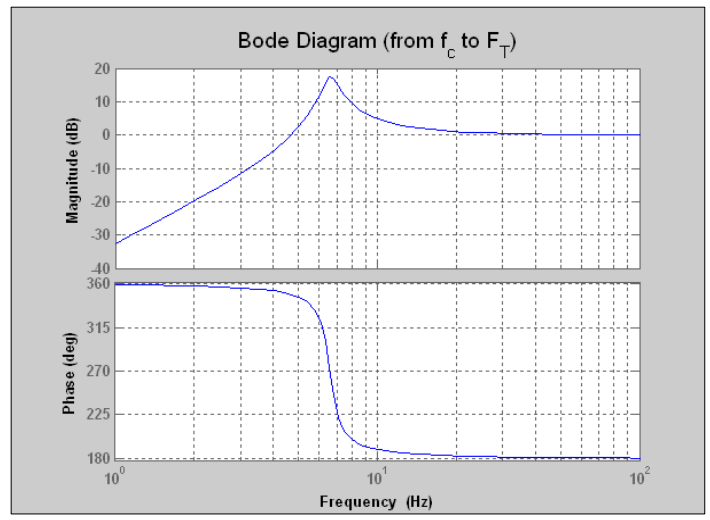

Fig. 3 Bode plot from $f_{c}$ to $F_{T}$ : case 2

Table 1 Parameters for hybrid mounts

\begin{tabular}{c|c|c|c}
\hline \hline Parameter & Value & Parameter & Value \\
\hline$m_{\text {equip }}$ & $500 \mathrm{~kg}$ & $m_{m}$ & $10.5 \mathrm{~kg}$ \\
\hline$c_{m}$ & $2,778 \mathrm{~N} /(\mathrm{m} / \mathrm{s})$ & $c_{c}$ & $0 \mathrm{~N} /(\mathrm{m} / \mathrm{s})$ \\
\hline$k_{m}$ & $859,849 \mathrm{~N} / \mathrm{m}$ & $k_{c}$ & $400 \mathrm{E} 6 \mathrm{~N} / \mathrm{m}$ \\
\hline
\end{tabular}

력이 하부로 전달되는 힘과의 전달률(bode 선도)을 보여주고 있다. 고주파수 영역에서 제어력의 전달률 이 감소하는 것을 알 수 있으며, 비교적 큰 제어력 이 필요한 것을 확인할 수 있다. 만약 Fig. 1(d)과 달리, 능동 요소의 제어력이 장비에 전달되지 않고

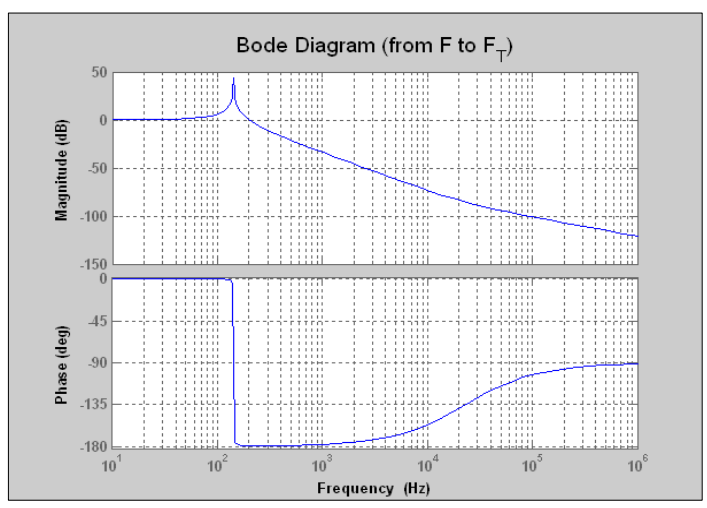

(a) From $F$ to $F_{T}$

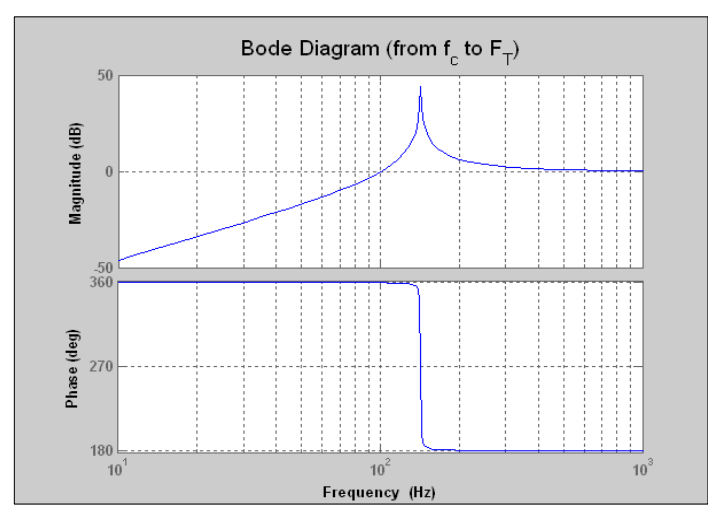

(b) From $f_{c}$ to $F_{T}$

Fig. 4 Bode plot from $F$ and $f_{c}$ to $F_{T}$ : case 3

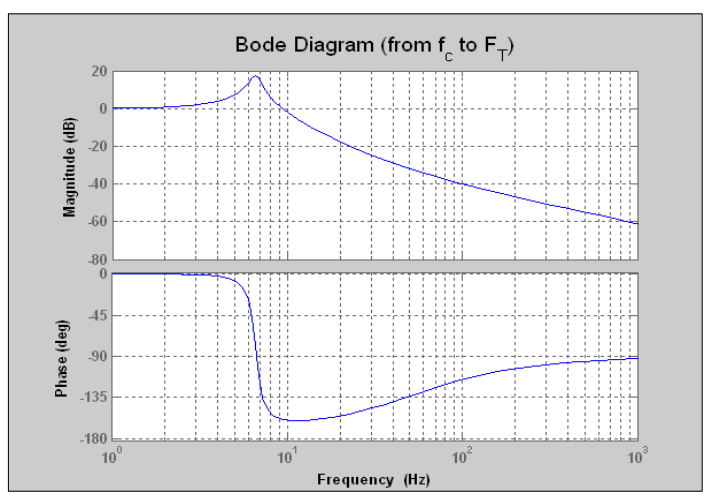

Fig. 5 Bode plot from $f_{c}$ to $F_{T}$ : case 4 


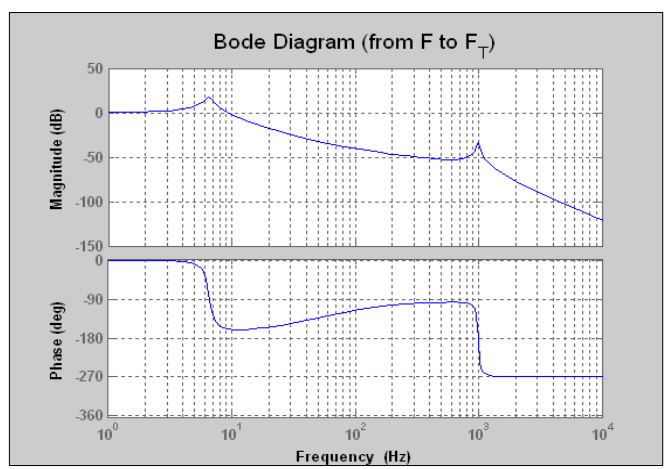

(a) From $F$ to $F_{T}$

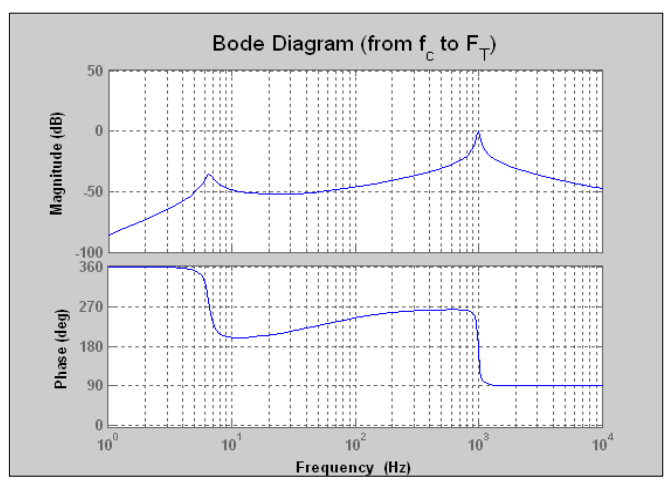

(b) From $f_{c}$ to $F_{T}$

Fig. 6 Bode plot from $F$ and $f_{c}$ to $F_{T}$ : case 5

base에 전달되도록 배치를 한다면, 하부로 전달되는 진동을 효과적으로 제어할 수 있을 것이다.

Fig. 6은 case 5에 대한 bode 선도를 보여주고 있 다. 좌측선도는 장비에 작용하는 힘 $(F)$ 과 수동 마운 트를 거쳐 하부로 전달되는 힘 $\left(F_{T}=c_{m} \dot{z}+k_{m} z\right)$ 의 전 달률을 보여주고 있다. Case 1 case 4와는 달리, 2자유도계 모델이므로 고유진동수에 해당하는 피크가 2개인 것을 알 수 있다. 낮은 고유진동수는 수동형 마운트에 의해, 높은 고유진동수는 능동형 요소에 의 해 나타나는 피크이다. 수동형 마운트의 특성으로 인 하여 고주파수 영역에서 전달률이 저감되는 것을 알 수 있다. 우측 선도는 제어력 $\left(f_{c}\right)$ 이 하부로 전달 되는 힘 $\left(F_{T}\right)$ 에 미치는 영향을 보여주고 있는데, 크 기가 $0 \mathrm{~dB}$ 이하로서 제어력이 잘 전달되지 않는다는 것을 알 수 있다. 따라서 진동저감을 위해서는 상대 적으로 큰 제어력이 필요함을 확인할 수 있다.

Case 6에 대한 bode plot은 Fig. 7에 보여주고 있 다. Case 5 와는 달리 제어력 $\left(f_{c}\right)$ 과 하부로 전달되는
힘 $\left(F_{T}=c_{c} \dot{y}+k_{c} y-f_{c}\right)$ 과의 전달률을 보면, 일부 영 역을 제외하고는 $0 \mathrm{~dB}$ 이상이 되는 것을 알 수 있 다(Fig. 7(a)), 또한 제어력을 제외한 하부로 전달되 는 힘과의 전달률 선도(Fig. 7(b))를 살펴보면, 대부 분의 영역에서 $0 \mathrm{~dB}$ 이상의 결과를 보이고 있다. 따라서 하부로 전달되는 진동 또는 하부로부터 유 입되는 진동을 효과적으로 제어할 수 있는 배치임 을 알 수 있다. 하지만 능동형 요소가 하단에 배치 되고, 일반적으로 능동형 요소가 충격하중에 매우 취약함으로, 하부로부터 유입되는 충격하중이 있는 경우에는 채택하기 어려운 배치임을 알 수 있다. Case 7은 앞 절에서 설명한 바와 같이 하부의 동강 성을 고려하는 경우이며, Fig. 8과 같이 case 6과 같은 특성을 보이고 있다. 따라서 하부로 전달되는 진동의 저감에 대해 효과적인 배치임을 알 수 있다.

\section{3. 배치형식에 따른 제어성능}

앞장에서 배치형식에 따른 복합형 마운트의 동특 성을 고찰하면서 제어력과 하부로 전달되는 힘과의 관계를 간략하게 살펴보았다. 수동형 마운트의 장점 을 유지하면서 능동형 요소의 제어력을 효과적으로 사용하기 위해서는 case 2, case 6 및 case 7 의 배 치방식이 좋은 것으로 고찰되었다. 3 개의 case에 대 해 대략적으로 복합형 마운트에서 능동형 요소의 제어성능을 예상할 수 있지만, 보다 자세한 고찰을 위해 제어기를 구성해 보았다. 일반적으로 적용하는 제어로직에 따라 다른 제어성능을 보이므로, 이 연 구에서는 가장 기본적인 제어로직으로서 PID 제어 기를 적용하여 수치 시뮬레이션을 수행하였다.

하부로 전달되는 힘의 저감을 목적으로 하고 있 으므로, 외부하중은 복합형 마운트의 상부에 설치되 는 장비의 자체 기진력에 의해서 발생하는 것으로 가정하였다. 발생하는 자체 기진력은 뚜렷한 주파수 특성을 가지고 있는 것이 일반적이지만, 전체적인 주파수특성을 살펴보기 위해 랜덤 형태의 하중이 작용하는 것으로 가정하였다. 수치 시뮬레이션에 적 용된 외부하중의 파형은 Fig. 9와 같으며, $10 \mathrm{~Hz}$ $1,000 \mathrm{~Hz}$ 의 주파수 성분이 포함되어 있다. PID 제 어는 하부로 전달되는 힘을 계측해서 되먹임 하도 록 설계하였으며, 하부로 전달되는 힘이 최소화할 수 있도록 각 게인을 설정하였다. 


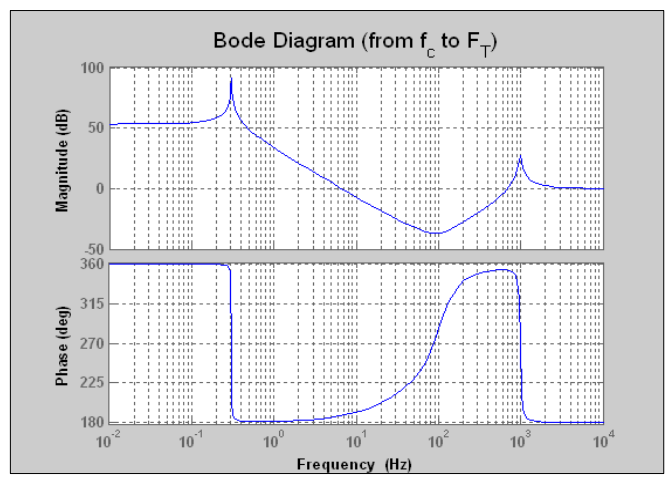

(a) From $f_{c}$ to $F_{T}$

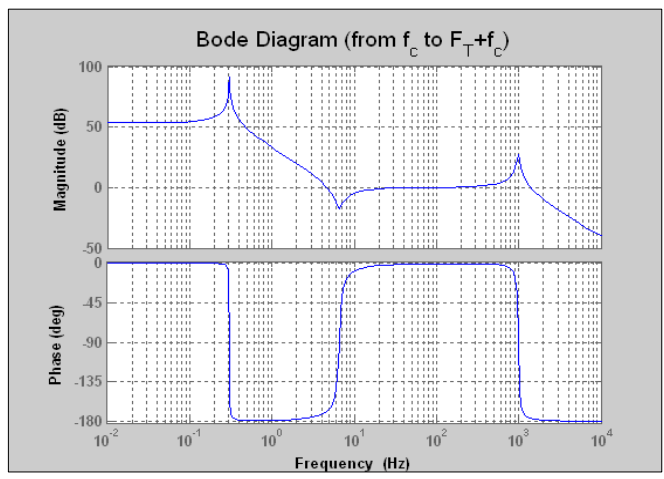

(b) From $f_{c}$ to $\left(F_{T}+f_{c}\right)$

Fig. 7 Bode plot from $f_{c}$ to $F_{T}$ and $\left(F_{T}+f_{c}\right)$ : case 6

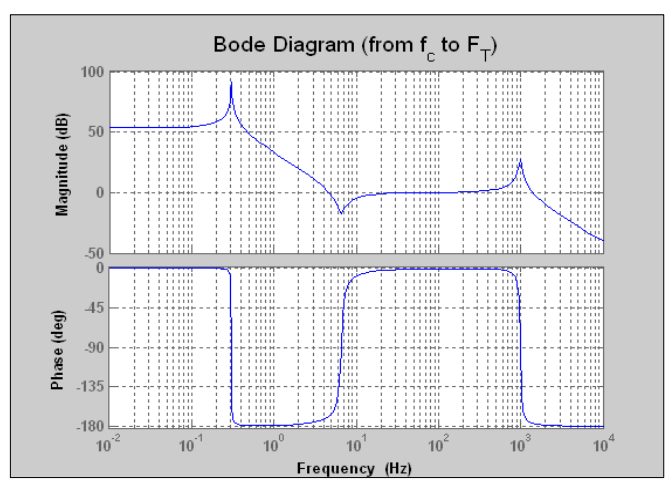

Fig. 8 Bode plot from $f_{c}$ to $F_{T}$ : case 7

Case 2에 대한 수치 시뮬레이션 결과는 Fig. 10 과 같으며, 능동형 요소의 작동 유무 $(\mathrm{OFF} / \mathrm{ON})$ 에 따른 하부로 전달되는 힘, 장비에 작용하는 가속도 및 능동형 요소에 의해 발생되는 제어력을 도시하였 다. Fig. 10에서 보는 바와 같이 최대 제어력이 약 $300 \mathrm{~N}$ 일 때, 하부로 전달되는 힘이 약 $50 \%$ 이상

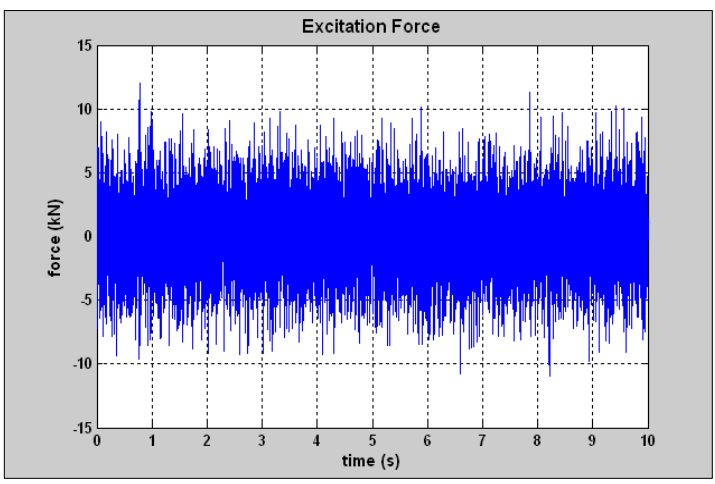

Fig. 9 Excitation force

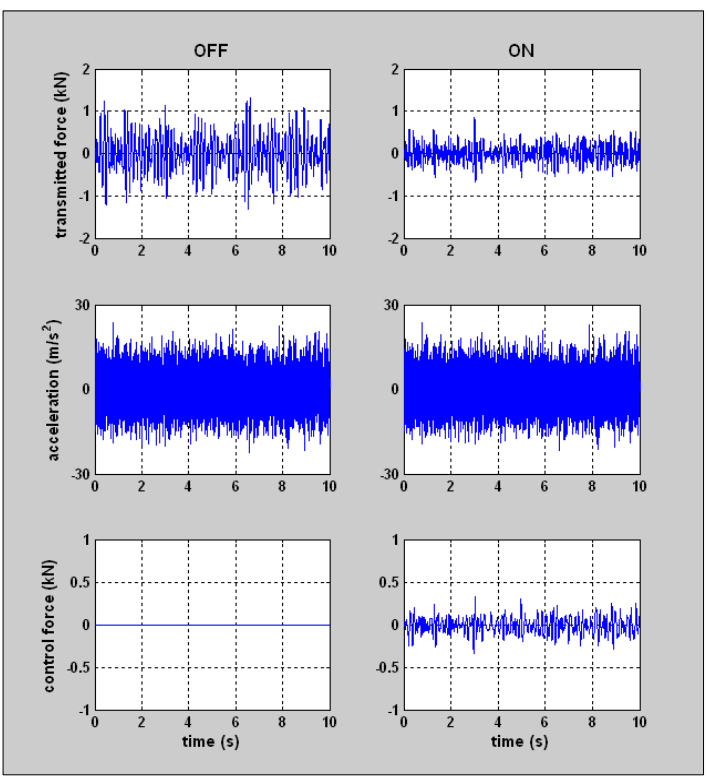

Fig. 10 Simulation result for case 2

저감된 것을 알 수 있다. 반면 장비의 가속도에는 거의 영향이 없는 것을 확인 할 수 있다.

Case 6과 case 7에 대한 수치 시뮬레이션 결과를 Fig. 11 및 Fig. 12에 나타내었다. Fig. 11을 살펴보 면, 제어력은 약 $2 \mathrm{kN}$ 이상 작용하였지만 하부로 전달되는 힘의 저감정도가 매우 미미한 것을 확인 할 수 있다. 또한 장비의 가속도 크기도 거의 변화가 없는 것을 알 수 있다. Fig. 7(a)를 보면, 기진력 영역 인 $10 \mathrm{~Hz} 1,000 \mathrm{~Hz}$ 에서 제어력 $\left(f_{c}\right)$ 이 하부로 전달되 는 힘 $\left(F_{T}\right)$ 으로 전달되는 크기가 $0 \mathrm{~dB}$ 이하인 것을 알 수 있다. 이것으로부터 제어효과를 높이기 위해서 는 매우 큰 제어력이 필요한 것을 알 수 있다. 


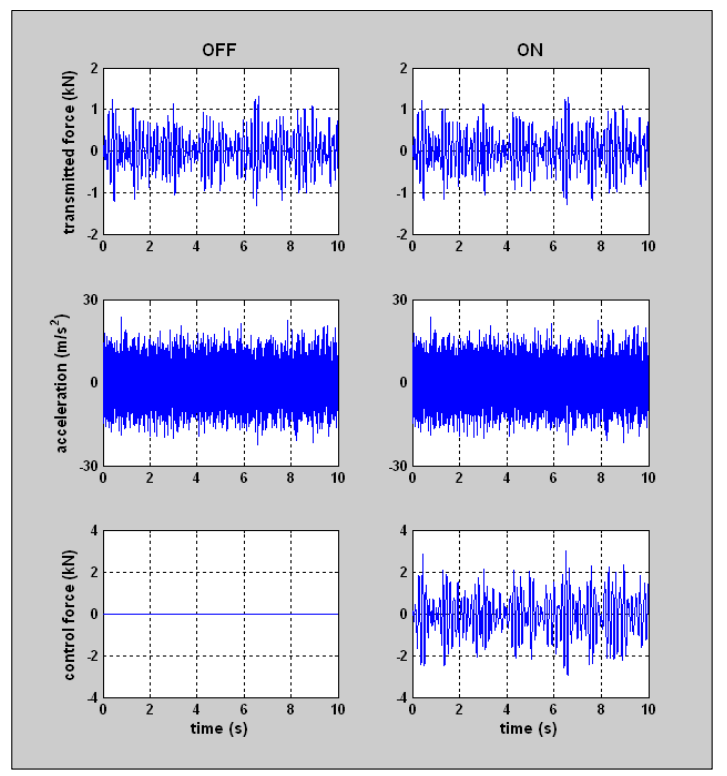

Fig. 11 Simulation result for case 6

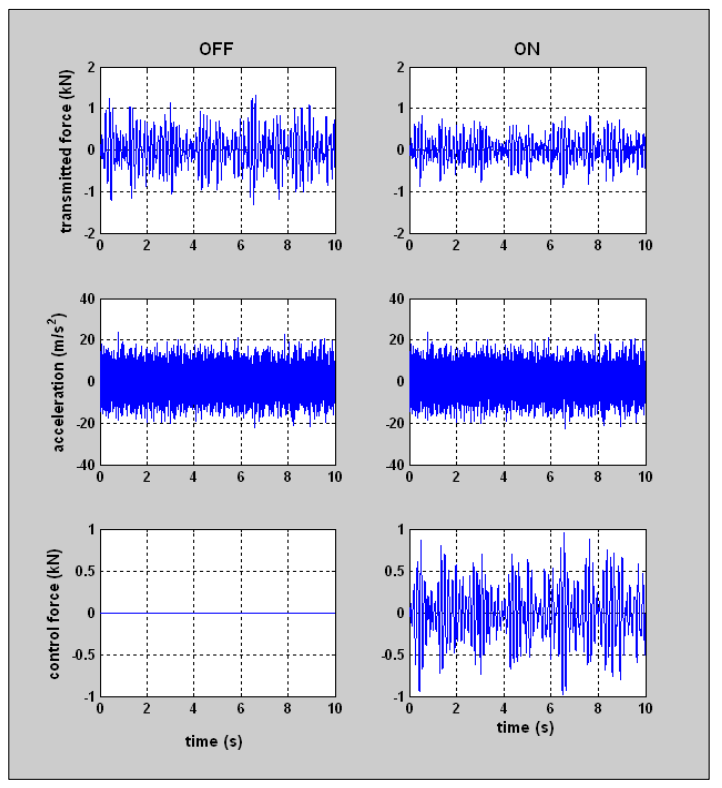

Fig. 12 Simulation result for case 7

Fig. 12를 살펴보면, 하부로 전달되는 힘이 저감된 것을 알 수 있으나, 장비의 가속도는 거의 변화가 없 음을 알 수 있다. 이때 작용하는 제어력은 약 $1 \mathrm{kN}$ 이하이다. Table 2에는 각 항목에 대한 RMS 값을 정 리하였다. Case 2, case 6 및 case 7인 경우, 각각 약 $6.7 \mathrm{~dB}, 0.1 \mathrm{~dB}$ 및 $3.5 \mathrm{~dB}$ 의 저감효과가 있는 것으로
Table 2 Summary of simulation results

\begin{tabular}{c|c|c|c|c}
\hline \hline \multirow{7}{*}{ Case } & Item & On & Off & $\begin{array}{c}\text { Reduction } \\
\text { ratio(dB) }\end{array}$ \\
\hline \multirow{7}{*}{2} & $\begin{array}{c}\text { Transmitted } \\
\text { force(N) }\end{array}$ & 206 & 445 & 6.7 \\
\cline { 2 - 5 } & $\begin{array}{c}\text { Acceleration } \\
\left(\mathrm{m} / \mathrm{s}^{2}\right)\end{array}$ & 6.3 & 6.3 & 0.0 \\
\cline { 2 - 5 } & $\begin{array}{c}\text { Control force } \\
(\mathrm{kN})\end{array}$ & 101 & 0 & - \\
\hline \multirow{2}{*}{6} & $\begin{array}{c}\text { Transmitted } \\
\text { force(N) }\end{array}$ & 438 & 445 & 0.1 \\
\cline { 2 - 5 } & $\begin{array}{c}\text { Acceleration } \\
\left(\mathrm{m} / \mathrm{s}^{2}\right)\end{array}$ & 5.2 & 5.2 & 0.0 \\
\cline { 2 - 5 } & $\begin{array}{c}\text { Control force } \\
(\mathrm{kN})\end{array}$ & 1,028 & 0 & - \\
\hline \multirow{2}{*}{7} & $\begin{array}{c}\text { Transmitted } \\
\text { force(N) }\end{array}$ & 296 & 445 & 3.5 \\
\cline { 2 - 5 } & $\begin{array}{c}\text { Acceleration } \\
\left(\mathrm{m} / \mathrm{s}^{2}\right)\end{array}$ & 5.2 & 5.2 & 0.0 \\
\cline { 2 - 5 } & $\begin{array}{c}\text { Control force } \\
(\mathrm{kN})\end{array}$ & 334 & 0 & - \\
\hline
\end{tabular}

계산되었다. 작용된 제어력은 각각 $101 \mathrm{~N}, 1,028 \mathrm{~N}$ 및 $334 \mathrm{~N}$ 이었다. 따라서 case 2 가 가장 좋은 제어성 능을 보이고 있는 것을 알 수 있다.

\section{4. 결 론}

이 논문에서는 수동형 마운트와 능동형 작동기로 구성되는 복합형 마운트의 배치방법에 대해 다루었 다. 수동형 요소를 기본으로 하는 복합형 마운트에 설치되는 능동형 요소의 연결 방식에 따라 대표적 으로 7개의 경우(case)를 제시하였다. 제시한 각각 경우에 대해 내부진동이 외부로 전달되는 성분(힘) 의 차단성능에 대해 bode 선도를 활용하여 동특성 및 제어성능을 비교·고찰해 보았다. 또한 차단성능 이 우수한 3 개의 경우에 대해 수치 시뮬레이션을 수행하였으며, 성능을 정량적으로 검토하였다. 이 연구에서 얻은 결과를 정리하면 다음과 같다.

- 복합형 마운트는 수동형 요소의 위쪽 또는 아 래쪽에 능동형 요소를 직렬로 연결하는 방식과 수 동형 요소의 주변에 병렬로 연결하는 방식이 있다. 또한 능동형 요소는 수동형 요소에 접촉식 또는 비 접촉식 연결 형태를 가질 수 있다.

- 고려한 7 개의 경우 중, 수동형 요소의 고유한 장점을 유지하면서 능동형 요소의 제어력을 효과적 
으로 사용할 수 있는 3 개의 경우(case 2, case 6 및 case 7)를 제안하였다. Case 2와 case 7은 능동형 요소가 비접촉식 연결 형태를 가지고 있는 반면, case 6은 접촉식 연결 형태로 설치된다.

- 수치 시뮬레이션의 결과를 살펴보면, case 2 가 정량적으로 가장 우수한 제어성능을 나타내고 있다. case 6 의 제어성능은 미미 하였으나, 기진력 주파수 특성을 고려하여 구성들의 요소를 설계한다면 좋은 제어성능을 보일 수도 있을 것으로 판단된다.

- Case 2인 경우는 수동형 마운트와 비접촉식 전 자기식 작동기 등으로 구현할 수 있으며, case 7은 수동형 마운트와 비접촉식 전자기식 작동기 또는 관성력형 작동기 등으로 구현할 수 있다. Case 6은 수동형 마운트와 적층형 압전작동기 등으로 구현할 수 있는 경우이다.

능동요소는 설계·개발 사양에 따라 사양이 상이 함으로, 이 연구에서는 능동요소 자체의 주파수 및 힘 특성 등을 고려하지 않았다. 새로운 복합형 마운 트를 개발할 경우, 이 연구의 결과와 함께 능동요소 의 동특성을 반드시 고려해야 할 것이다.

\section{후 기}

이 논문의 연구는 국방과학연구소의 연구지원으 로 수행되었음을 밝힙니다.

\section{참 고 문 헌}

(1) Moon, S. J., Jung, H. J., Shin, Y. H., Jang, D. D., Jeong, J. A. and Moon, Y. J., 2011, Development of a Hybrid Mount System Combined Airspring with Piezostack Actuator for Microvibration, Transactions of the Korean Society for Noise and Vibration Engineering, Vol. 21, No. 1, pp. $56 \sim 65$.

(2) Moon, S. J., Park, S. H., Jeong, J. A., Huh,
Y. C., Kim, C. H. and Choi, S. M., 2011, A Study on the Development of a Hybrid Electromagnetic Actuator Against Microvibration, Transactions of the Korean Society for Noise and Vibration Engineering, Vol. 21, No. 5, pp. 475 483.

(3) An, C. H., Yim, K. H., Jin, K. B. and Rim, K. H., 2007, Active Control of Vibration Isolation Table Using Air-spring, Transactions of the Korean Society for Noise and Vibration Engineering, Vol. 17, No. 7, pp. 565 571.

(4) Shin, Y. H. and Kim, K. J., 2009, Performance Enhancement of Pneumatic Vibration Isolation Table in Low Frequency Range by Time Delay Control, Journal of Sound and Vibration, Vol. 321, No. 10, pp. 537 553.

(5) Lee, B. H. and Lee, J. W., 2007, Optimal Design of Electromagnetic Type Active Control Engine Mount in Consideration of Actuator Efficiency, Proceedings of the KSNVE Annual Spring Conference, pp. 1112 1118.

(6) Lee, D. H., Son, J. W. and Choi, S. B., 2009, A New Type of Active Engine Mount System Featuring MR Fluid and Piezostack, Transactions of the Korean Society for Noise and Vibration Engineering, Vol. 19, No. 6, pp. 583 590.

(7) Moon, S. J., Kwak, J. S., Chung, J. H., Ji, Y. J., Yoon, J. S., Choi, S. M., Lee, H. Y., Jung, W. J. and Ki, D. J., 2010, A Study on the Hybrid Mount against Vibration and Shock for Naval Ships, Shock and Vibration, Vol. 17, pp. 269 283.

(8) Oh, J. S., Choi, S. B., Nguyen, V. Q., Moon, S. J. and Choi, S. M., 2011, Evaluation of Vibration Control Performance for Active Hybrid Mount System: Experimental Investigation, Transactions of the Korean Society for Noise and Vibration Engineering, Vol. 21, No. 5, pp. 455 460. 